\title{
A manera de presentación
}

Presentamos a la comunidad académica, nacional e internacional, la edición $\mathrm{N}^{\circ} 8$ de la revista de museología Kóot, con el firme compromiso de fomentar el pensamiento crítico, promover la investigación social y difundir ideas para enriquecer el debate de los temas culturales relevantes y de interés a la sociedad moderna.

La revista es una publicación de la Universidad Tecnológica de El Salvador, Utec, editada por la Dirección de Cultura, y en ella se presentan pero también se analizan fenómenos socioculturales, históricos y antropológicos, desde la visión museística; y a la vez, se incorporan otro tipo de enfoques académicos para darle una mayor riqueza al debate de los temas que más interesan a la comunidad universitaria de nuestro país y de la región centroamericana.

En esta revista el lector podrá encontrar un análisis sobre la vida del insigne militar, Francisco Morazán, realizado por el catedrático e investigador hondureño Jorge Alberto Amaya Banegas, el artículo expone la construcción de ciertos imaginarios de nación, y describe cómo los reformadores se dieron a la tarea de construir un nacionalismo basado en la creación del "Panteón de los Héroes Nacionales", exaltando a Morazán como el principal prócer reinante de ese "Panteón sagrado". Asimismo, presenta algunos tópicos que a juicio del autor son herencias o legados fundamentales del genio de Morazán para la región centroamericana.

El antropólogo, Julián Barrera Tolentino, presenta información valiosa sobre Suchitoto y su principal actor, Alejandro Cotto, cineasta y promotor cultural que puso a su ciudad, en el mapa de miles de turistas nacionales e internacionales.

El historiador Chester Urbina Gaitán, describe y analiza desde la figura del Lic. Cleto González Víquez (1937) exmandatario, aspectos referentes a la moral y la identidad de una nación que ha sabido escudriñar las ventajas y desventajas donde el Estado es la construcción directa y única de la clase dominante y se construye para regular y encauzar el conflicto social, pero siempre sacando lo positivo de ello de los gobernantes que han liderado el destino de esa nación. Democracia, compromiso y valor patriótico han sido ejes claves que se han explotado en la construcción de la nación de Costa Rica. 
La antropóloga y periodista, Carmen Molina Tamacas reproduce en esta edición, una entrevista que ella retomó y que fue hecha a Elisa Pritzker, titulado "A través del lente de la cultura urbana".

Sigfredo Cabrera Rajo radicado, académico y radicado en España ofrece un oportuno artículo sobre la introducción histórica de los negros en esta parte del mundo. Su contribución en concreto, versa sobre "Los esclavos negros africanos en el reino de Guatemala y las provincias de El Salvador y Honduras.

Julio Martínez, director de la Escuela de Antropología de la Universidad Tecnológica de El Salvador, presenta un artículo titulado "Mapa de muros y cristianos en El Salvador". Se trata de un artículo relacionado con los Historiadores en el imaginario salvadoreño. Es un trabajo de investigación de campo para identificar en qué lugares hay aún presencia de grupos de danzantes e historiantes.

El filósofo Rubén Fúnez, catedrático e investigador de la Escuela de Antropología de la Utec hace una reflexión sobre las categorías filosóficas para el análisis de la realidad salvadoreña. Se trata de un artículo novedoso en su género que pretende ir espigando aquellas categorías filosóficas fundamentales que permitan al ser humano dar cuenta de la realidad en la que estamos situados.

En esa misma línea, el filósofo y docente de la Universidad Centroamericana, UCA, Dr. Héctor Samour, escribe ahora un ensayo referente a la filosofía griega.

El Filólogo Ernesto Rivas Arévado tratando de hacer un estudio comparativo pero de raigambre histórico escribe pero a la vez analiza los restos encontrados frente a la iglesia parroquial San Miguel Arcángel en 1972 que fueran los fundamentos de la primera iglesia edificada en a mediados de 1600. Con un artículo titulado "La Roseta Hexapétala y la cruz solar en Ilobasco", el investigador nos ofrece una panorámica de esas bases ahora parte importante del patrimonio histórico de la ciudad.

Julián Barrera Tolentino con un artículo titulado "Alejandro Cotto: Cine y aporte cultural a Suchitoto", nos lleva al mundo del cineasta y gestor cultural sichitotense Alejando Cotto insertado en su lugar de origen Sichitoto- pero también como profesional. El el quehacer profesional de un cineasta que hasta el último día de su vida luchó por hacer de su lugar de origen un oasis cultural en todas sus aristas.

Ramón D. Rivas, Director de Cultura de la Utec y editor de la revista Kóot, reflexionando sobre el valor humano del patrimonio edificado analiza el caso de la ciudad de Suchitoto de la que ofrece ahora un artículo 
titulado "Suchitoto, un patrimonio que se transforma: ¿Para quién? ¿Para qué? ¿Y sus herederos? Las preguntas hablan por sí y para si y es precisamente de ellas en donde la reflexión tiene punto de arranque.

No es en vano recordar que la revista Kóot es única en su género, elaborada por un equipo de trabajo que se esfuerza por ofrecer contenidos frescos, oportunos y escritos por reconocidos investigadores, articulistas, ensayistas y monografistas que buscan responder y analizar los fenómenos que acontecen y/o nacen de la realidad misma de las sociedades.

De ahí la importancia de cada una de sus ediciones, todas indexadas para el acceso a toda la comunidad universitaria salvadoreña; y no solo de nuestro país, sino también de otras partes del mundo que ingresan a nuestro sitio http://biblioteca.utec.edu.sv/koot/index.php/ koot para actualizar sus conocimientos antropológicos, museológicos, sociológicos, históricos o filosóficos.

Nos agrada saber que hay personas amantes de la lectura, investigadores y analíticos que acuden a nuestra revista para fundamentar sus teorías, sus análisis y su pensamiento crítico académico de la realidad existente. De ahí nuestro compromiso de exigir que los textos cumplan con los más altos estándares académicos (aunque los conceptos vertidos son de exclusiva responsabilidad de cada autor), para que la información sea fidedigna e imparcial.

De esta manera, nuestro gran objetivo: proveer información basada en la investigación documental, convierte a la revista Koót en una fuente de conocimiento para aquellos que buscan la verdad de las cosas, una explicación de la realidad y de su incidencia en la humanidad.

\author{
Dr. Ramón D. Rivas \\ Director. \\ Dirección de Cultura
}

Editor. Revista de Museología Kóot

Universidad Tecnológica de El Salvador 


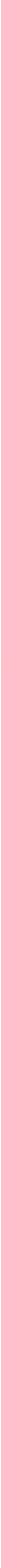

